\title{
Diversidade e transdisciplinaridade no e do jornalismo
}

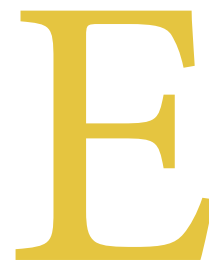

timologicamente, o termo diversidade remete àquilo que é variado, plural, diverso, que expressa a multiplicidade de modos de saber e de se distinguir algo ou alguém. Por isso, podemos falar de diversidade humana, cultural, linguística, religiosa, sexual, biológica etc. A diversidade é inerente à prática jornalística, seja pela multiplicidade de temas possíveis de serem tratados como também das abordagens que podem ser feitas pelo jornalismo.

De modo correlato, porém mais relacionado ao jornalismo como campo de pesquisa, a transdisciplinaridade nos remete à uma compreensão da realidade além e através das diversas disciplinas, constituindo uma abordagem científica que busca entender a complexidade dos fenômenos sociais e da diversidade de formas de conhecimento. Partindo dessas duas características, de diversidade e de transdisciplinaridade, apresentamos a segunda edição semestral de 2018, do volume 15 da revista EJM, com dez artigos de Temas Livres que abarcam abordagens sobre "Diversidade, produção e recepção", uma entrevista e uma resenha.

Assim, a presente edição da EJM abre com o artigo de Leandro Rodrigues Lage, que explora contribuições da hermenêutica de Paul Ricoeur para uma teoria da narratividade jornalística. O pesquisador aborda a noção de narrativa jornalística "à luz da operação mediadora da narração, que se desenvolve entre a experiência dos acontecimentos e os processos de leitura e interpretação, por meio da configuração de um enredo ou intriga". O argumento, como resume o pesquisador, tensiona especialmente três percepções sobre a dimensão narrativa do jornalismo: que ela se fundamenta no fato de que é intrínseco à instância jornalística contar histórias; que ela é uma modalidade, gênero ou estrutura textual e discursiva; e que a qualidade narrativa do jornalismo ameaça a construção das relações de referencialidade com os acontecimentos, orientadas pelo ideal da objetividade.

Também em uma perspectiva interdisciplinar, os dois artigos seguintes desta edição trazem contribuições dos estudos de gênero para pensar o jornalismo e/ou produção midiática na sua relação com a sociedade. No primeiro deles - "O jornalismo sob o prisma de gênero: discurso e produção de sentidos na relação texto-leitor" -, Pâmela Caroline Stocker apoia-se nos estudos feministas pós-estruturalistas e no aporte teórico-metodológico da Análise de Discurso (AD) para analisar os sentidos produzidos pelos leitores em 927 comentários no Facebook oriundos de duas reportagens jornalísticas que tratam sobre identidade de gênero e transexualidade. A partir da observação da relação entre texto e leitor sob o prisma de gênero, o estudo mostra que "os sentidos ligados à empatia surgiram apenas a partir da reportagem construída com viés mais próximo ao que denominamos como valores do feminino". 
No segundo artigo desta edição a abordar a relação entre mídia e gênero, Fernanda Nascimento, Jéssica Gustafson e Joana Maria Pedro analisam a recepção das pessoas trans sobre a série Quem sou Eu?, exibida pelo programa Fantástico, da Rede Globo, em 2017, cuja temática foi a de identidades trans. Apoiam-se em premissas teóricas dos estudos culturais e queer e na utilização de etnografia virtual para analisar comentários nos vídeos da série, disponibilizados na página de Facebook do programa, visando compreender os sentidos produzidos por pessoas trans. Mostram que há "o engajamento das pessoas trans em desmitificar preconceitos e a celebração da visibilidade, vista como possibilidade de esperança para uma vida com menos discriminações".

O modo como o jornalismo trata as demandas dos cidadãos e a ação de movimentos da sociedade civil, tanto no âmbito da cobertura jornalística de mídias locais e alternativas ou das tradicionais e hegemônicas, também está presente em três trabalhos da presente edição. Em "Jornalismo local e cidadania: análise de mídias em Iporá (GO)", Karen Terossi, Maximiliano Martin Vicente, Clara Allicia Rosa de Souza investigam como o jornalismo produzido em Iporá (GO) apresenta questões relativas a direitos dos cidadãos. Utilizam a análise de conteúdo, com análise estatística e considerações qualitativas sobre a amostra, composta por conteúdo de um radiojornal diário (Jornal Rio Claro) e um site noticioso (Oeste Goiano). Os resultados evidenciam que a mídia local privilegia informação para a cidadania (prestação de serviços, informação crítica e divulgação de políticas públicas locais).

Já a pesquisadora Aparecida Zuin analisa a relação entre mídias jornalísticas e os movimentos sociais que defendem o direito à terra, buscando apreender a produção de sentidos acerca das ações deste tipo de movimento. A partir de análise qualitativa fundamentada em aportes teóricos da comunicação, semiótica e do direito à terra, o estudo investigou os discursos de três jornais eletrônicos de maior circulação em Rondônia ( Jornal Rondônia ao Vivo - J1; Jornal Diário da Amazônia - J2; e Jornal Folha Nobre - J3), entre os anos de 2014 a 2016, buscando apreender os sentidos produzidos sobre movimentos que atuam na defesa do direito à terra naquele estado: a Liga Camponesa dos Pobres (LCP) e o Movimento dos Trabalhadores Rurais Sem Terra (MST). Segundo a autora, a análise permite inferir que os conflitos no campo em Rondônia e o crescimento do número de homicídios de agricultores militantes da LCP e do MST têm relações com a criminalização desses movimentos por parte das mídias.

Também interessado na relação entre mídias jornalísticas e movimentos da sociedade civil, o estudo de Kamila Bossato Fernandes dedica-se a investigar a cobertura jornalística audiovisual sobre a greve geral realizada no Brasil em 28 de abril de 2017. Realiza uma análise multimodal de reportagens produzidas por dois dos principais telejornais brasileiros (Jornal Nacional/TV Globo e Jornal da Record/RV Record) e quatro meios alternativos online (Jornalistas Livres, Coletivo Nigéria, Marco Zero Conteúdo e Coletivo Catarse), com o objetivo de identificar estratégias discursivas utilizadas nas narrativas jornalísticas audiovisuais. Entre as conclusões e contrastes observados, a autora destaca que as mídias tradicionais buscaram realçar sua legitimidade a partir das vozes de pessoas comuns, enquanto as mídias alternativas fortaleceram fontes contra-oficiais, sobretudo sindicalistas.

A crítica de coberturas jornalísticas é uma constante em estudos da área. Em uma pesquisa comparativa sobre a crítica de cobertura em um periódico científico espanhol (Estudios Sobre el Mensaje Periodística) e um periódico brasileiro 
(Estudos em Jornalismo e Mídia), Gislene Silva analisa artigos que investigam o tratamento jornalístico em diferentes coberturas. A pesquisa, que objetiva teorizar sobre "como criticam os que criticam" e sistematizar formas de apreciação de diferentes objetos da mídia, conclui que os pesquisadores criticam as coberturas jornalísticas pelos enquadramentos adotados no processo de formação da opinião pública e pelas omissões contra o poder hegemônico: não trabalham "contra preconceitos, estereótipos, discriminações e desigualdades sociais, mas sim para a manutenção do status quo".

No oitavo artigo desta edição, "Entre as fronteiras do aceitável: o valor-notícia como legitimador do jornalismo como gestor de consenso", Francisco Verri dialoga com os estudos sobre noticiabilidade e sua relação com a política, defendendo o argumento segundo o qual os valores-notícia operam como um mecanismo da falta de pluralidade dos acontecimentos na na cobertura jornalística da política. Para o pesquisador, há uma correlação entre os valores-notícia e as hegemonias políticas. Segundo ele, "esses valores (re) significam o que é importante ser noticiado, legitimando uma agenda de grupos e atores hegemônicos". O resultado seria a promoção de pautas governamentais e fontes oficiais, e a marginalização de acontecimentos de grupos com menor expressão midiática.

Ainda no âmbito da relação entre mídias e política, em especial a política partidária e institucional, Deysi Cioccari e Simonetta Persichetti fundamentam-se no conceito de sociedade do espetáculo, de Guy Debord, e de estudos da imagem pública, a partir de Maria Helena Weber, para discutir o cenário da política contemporânea no Brasil. Analisam a disputa entre atores políticos e mídia na construção da imagem, a partir das transformações advindas com as novas tecnologias. Exploram, para isso, os casos das práticas de comunicação dos prefeitos João Doria Junior, de São Paulo, Nelson Marchezan Junior, de Porto Alegre, e do então deputado federal e presidenciável em 2018, Jair Bolsonaro, um dos mais atuantes em redes sociais digitais.

Encerrando a seção de Temas Livres, a revista EJM traz o estudo realizado por Francisco Eduardo Gonçalves, Isa Coelho Stacciarini e Solano Nascimento, que analisa o uso da Lei de Acesso à Informação por parte de jornalistas. A pesquisa, realizada em 2017, mostra que jornalistas têm usado efetivamente a LAI para obter informações. No entanto, o uso ainda é pequeno. Apenas um grupo reduzido, naquele ano, fez da LAI uma ferramenta de uso contínuo para a apuração jornalística.

Na seção Entrevista, o infografista Jaime Serra é entrevistado por William Robson Cordeiro Silva, doutorando do PPGJOR/UFSC, sobre o papel da infografia no jornalismo. Na entrevista, Silva relata que "Serra aborda desde o futuro da infografia jornalística até as ferramentas utilizadas para a produção de suas peças [...] e também explica que a crise que afeta o jornalismo e as empresas jornalísticas em especial, atingiu em cheio os departamentos de arte, mas sente que o prejuízo para a infografia tem sido menor".

A edição é encerrada com a resenha "Uma proposta de reforma para a ética jornalística", de Rogério Christofoletti, professor e pesquisador do PPGJOR/ UFSC, sobre o livro "Disrupting Journalism Ethics. Radical Change on the Frontier of Digital Media”, de autoria de Stephen J. A. Ward, que, segundo Christofoletti, “é um dos autores mais prolíficos e influentes do lamentavelmente restrito clube de eticistas da área”. 
Agradecemos a participação dos(as) autores(as), assim como a preciosa colaboração de nossa equipe de avaliadores(as) e de revisores(as) desta edição.

Boa leitura!

Daiane Bertasso e Terezinha Silva 